\title{
Genetically Engineering Coral for Conservation: Psychological Correlates of Public Acceptability
}

\author{
Aditi Mankad*, Elizabeth V. Hobman and Lucy Carter \\ CSIRO Synthetic Biology Future Science Platform, CSIRO Land and Water, Brisbane, QLD, Australia
}

Coral bleaching contributes to widespread reef loss globally, including Australia's World Heritage site, the Great Barrier Reef. Synthetic biology offers the potential to isolate and cultivate strains of coral that can naturally withstand higher sea surface temperatures associated with climate change. A national survey was conducted ( $N=1,148$ Australians) measuring psychological predictors of support for a synthetic biology conservation solution to coral loss. The analysis showed a partially mediated path model was useful in explaining a significant amount of variance in public support for the development of genetically engineered coral for conservation $\left(R^{2}=0.40\right)$ and

\section{OPEN ACCESS}

Edited by:

Wen-Cheng Wang,

National Taiwan Normal University,

Taiwan

Reviewed by:

Gael John Lecellier,

Université de Versailles

Saint-Quentin-en-Yvelines, France

Susana M. F. Ferreira,

Polytechnic Institute of Leiria, Portugal

*Correspondence:

Aditi Mankad

aditi.mankad@csiro.au

Specialty section:

This article was submitted to

Marine Conservation

and Sustainability,

a section of the journal

Frontiers in Marine Science

Received: 16 May 2021 Accepted: 20 October 2021

Published: 18 November 2021

Citation:

Mankad A, Hobman EV and

Carter L (2021) Genetically Engineering Coral for Conservation: Psychological Correlates of Public

Acceptability.

Front. Mar. Sci. 8:710641. doi: 10.3389/fmars.2021.710641 in willingness to visit parts of the Great Barrier Reef where genetically engineered coral had (hypothetically) been introduced $\left(R^{2}=0.24\right)$. Participants were moderately strongly supportive of technology development and were most keen to implement genetically engineered coral with between 50 and $70 \%$ of reef remaining intact; recent estimates of coral cover across the Great Barrier Reef are well below that already. There was a negative association between perceived risks of genetically engineered coral and public support; however, perceived benefit of genetically engineered coral in protecting the reef and relative advantage of a synthetic biology solution over existing protection strategies were the most influential predictors of public support. The findings suggest that the general public are not averse to the development of a synthetic biology solution for restoring the reef, and they may be especially influenced by whether the synthetic biology solution is shown to be efficacious, particularly in comparison to other conservation solutions. However, support for a synthetic biology intervention is conditional and many participants expressed concerns about possible long-term impacts on humans, animals, and the environment as a result of deploying engineered coral.

Keywords: risk perception, Great Barrier Reef, climate change, public survey, synthetic biology

\section{INTRODUCTION}

The Great Barrier Reef (GBR) is a complex ecosystem that is home to a plethora of sea flora and fauna, including hundreds of species of coral. The GBR has experienced, and continues to experience, widespread pressures including rising sea surface temperatures, crown-of-thorns starfish predation, land run-off and cyclone damage (Great Barrier Reef Marine Park Authority, 2019). It has been estimated that if the current rate of coral depletion continues, up to $75 \%$ of the world's coral will face high-to-critical threat levels by 2050 (Burke et al., 2011). Thus, there is a need 
for development of proactive coral restoration methods, to be used in conjunction with behavioral and institutional changes associated with lowering global greenhouse gas emissions (Taylor et al., 2019). The development of heat tolerant corals is one restoration approach, amongst a range of prevention and restoration options (Bay et al., 2019); the appeal of this genebased solution is its potential to scale-up and positively influence marine habitat sustainability.

While current advances in thermal-tolerant corals involves selective breeding approaches, application of a genetic solution at scale will require more novel methods such as synthetic biology. Synthetic biology (synbio) is a new and emerging area of research, which offers a potential suite of solutions to mitigate some of the negative impacts that coral reefs face due to environmental and biological factors. Rather than targeting extraneous factors contributing to coral reef degradation, synthetic biology can redesign DNA structures of the coral itself, making it more resilient to threats. Specifically, the synthetic biology technology identifies natural gene variants in existing coral that enhance their ability to withstand higher temperatures and introduces these into other coral species that are not as heat resistant (Bay et al., 2019).

Although technological advances in coral breeding continue to be developed and tested in laboratory settings, there has been a dearth of research exploring stakeholder perspectives toward novel solutions in the reef. The GBR holds special cultural, social and economic value to many communities in Australia, including those whose livelihoods depend on the reef, such as eco- and marine tourism industries (Marshall N. et al., 2019). Importantly, the GBR region is a source of livelihood and a place of deep cultural significance for Aboriginal and Torres Strait Islander peoples in the region, some of whom are the Traditional Owners and custodians of the GBR region and have been for over 60,000 years (Great Barrier Reef Marine Park Authority, 2020b). It is therefore critical to understand relevant stakeholder perspectives alongside technology development and ground-truth real-world implementation considerations.

\section{Public Sentiment Toward Protecting the Great Barrier Reef}

As a World Heritage area, the Great Barrier Reef is an international icon and research on public sentiment toward the reef has often reflected on the role that place plays in the lives of people, their attachment to the place, as well as economic and emotional connectedness (Lewicka, 2011). More recently, with the increasing frequency of extreme climate events causing mass coral bleaching (Stuart-Smith et al., 2018; Great Barrier Reef Marine Park Authority, 2020a), the public benefits derived from these areas (e.g., tourism and recreation) are being negatively affected. This has led to greater investment in promoting conservation goals in the area, helping stakeholders navigate social and economic benefits derived from the region and interact with the environment in a more ecologically sustainable way (Dobbs et al., 2011; Goldberg et al., 2016).

Public desire to protect the GBR is strong, not just in Australia, but globally. For example, recent social science research has found that there is a general willingness to support action to protect the reef among GBR residents, international tourists, and the broader Australian populace (Curnock et al., 2019; Taylor et al., 2019; Westoby and McNamara, 2019). It has been proposed that significant coral bleaching events have increased the public's awareness of the threat of climate change on the reef and simultaneously reminded people of the reef's value and the importance of protecting it (Curnock et al., 2019; Westoby and McNamara, 2019). In turn, rising protective sentiment and increased concern among the population could well be leveraged to initiate collective action. Unsurprisingly, the Australian general public tend to be more supportive than unsupportive of a range of different methods for reef restoration, although a considerable proportion remain neutral in their support (Taylor et al., 2019). Of relevance to the current study, approximately $40 \%$ of participants in Taylor et al.'s (2019) study indicated acceptance (i.e., higher than the mid-point of the scale) of genetically modified heat resistant coral to restore the GBR. However, compared to some of the other manual reef restoration options (e.g., rubble stabilization, manual removal of pests such as crown-of-thorns starfish), genetic modification was generally viewed as a riskier option and elicited higher levels of opposition amongst participants.

An important limitation of past research on protective action in the reef is understanding public motivation to accept novel technologies in such a contested space (Lane and Robinson, 2009). What's more, public willingness or intention to engage meaningfully with the place once a novel solution is implemented is also not yet understood. Yet, the literature suggests that the sociocultural implications of a biotechnical intervention in the GBR would be wide-ranging, affecting livelihoods, industry, and deeply held values about the natural wonder (e.g., Goldberg et al., 2016; Marshall N. A. et al., 2019).

\section{Perceived Threat as a Motivator}

As recent coral bleaching events have increased public awareness of threats to the reef, raising protective sentiments and the potential for collective action, it is useful to explore psychological theories relevant to fear appeals and protective behavior (Curnock et al., 2019; Westoby and McNamara, 2019). Fear appeals are thought to influence risk-related attitudes, intentions and behaviors (Tannenbaum et al., 2015). They are comprised of three main components: fear of the threat, threat noxiousness (severity), and perceived efficacy of threat mitigation (Witte, 1992). When people are faced with a threat and feel vulnerable to it, they will go through an evaluative process to determine whether the threat is strong enough to warrant action, whether recommended responses will ameliorate the threat, and the relevant response costs (e.g., time and effort) associated with action (Rogers and Mewborn, 1976). Empirical research utilizing fear appeal perspectives, particularly protection motivation (PM) research, has advanced our understanding of risky or preventive behaviors across a multitude of environmental contexts, from understanding responses to biosecurity and natural disasters (e.g., floods, wild fires, and earthquakes) (e.g., Grothmann and Reusswig, 2006; Martin et al., 2007; Blunt, 2012; Tang et al., 2018) to explaining pro-environmental behavior (e.g., Marquit, 2008; Mankad et al., 2013; Zhao et al., 2016; Kothe et al., 2019). 
In the present context, this study argues that a fear appeal need not necessarily refer to a direct personal threat, but that the framing would work equally well when referencing perceived threat toward a broader environmental conservation issue. It is proposed that when confronted with a threatening environmental event (i.e., significant reef loss), people would still evaluate the level of threat severity from a personal perspective. It is further argued in this study that while direct personal vulnerability to the conservation threat of coral reef loss would not make sense, a more appropriate and implicit framing of vulnerability toward a broader environmental threat could be measured by evaluating the threshold at which a mitigating solution (genetically engineered coral) is needed/introduced into the reef. Typically, the outcome of this threat appraisal process is an intention to accept or engage with (or not) the protective response (Rogers, 1983). This motivation to engage or accept a protective response is further influenced by one's belief that carrying out the recommended actions can successfully remove the threat (i.e., response efficacy). It is argued that the threat appraisal process will be an important framework for understanding motivations to not only support novel synbio interventions in the reef to mitigate a significant threat (i.e., coral degradation and loss), but will also influence one's behavioral intention to support a genetic intervention (i.e., through willingness to visit the GBR where the genetic solution has been deployed).

\section{Relative Advantage}

A limitation of fear appeals in explaining motivation toward engaging in recommended behaviors is the inability to adequately capture mental trade-offs involved in complex decision-making in the context of viable alternatives. For example, why would people choose a synthetic biology solution to coral degradation over a manual solution? Given the perceived risks and benefits, at what point would a genetic solution be acceptable? Numerous solutions to the degradation of the GBR, and indeed coral reefs worldwide, have been proposed and many are being implemented or trialed around the world (Taylor et al., 2019). Some examples of these solutions include: increased shading using surface films or cloud brightening; increasing heat resistance of corals using natural breeding techniques or genetic modification; infrastructure solutions (e.g., rubble stabilization or humanmade reef structures); and pest control using biological agents or manual removal (Taylor et al., 2019). Several of these new approaches carry their own advantages and limitations, as well as unknown long-term consequences.

A diffusion of innovation theory perspective would suggest that trade-offs are evident in assessing the relative advantage of an innovation; that is, the degree to which the innovation is seen as better than what is currently available or being deployed (Valente and Rogers, 1995; Rogers, 2004). Rogers' relative advantage attribution considers increases in efficiency, efficacy, economic appeal, and future benefit. Past research has consistently demonstrated that relative advantage can directly and positively influence the rate of innovation adoption (Pannell et al., 2006; Kuehne et al., 2017).
The relative advantage of an innovation will, of course, depend on individuals' unique set of needs, the innovation context and the ultimate goals of the innovation relative to the individual (Rogers, 2003; Pannell et al., 2006). Part of this assessment is also the consideration of riskiness, whether in terms of efficacy, unexpected/unintended outcomes or costs associated with changing from one innovation to another (Marra et al., 2003; Pannell et al., 2006). Risk and uncertainty feature strongly in the literature on new, emerging and controversial technologies (e.g., nanotechnology, carbon capture, and storage; Barnett et al., 2007; Kirk et al., 2019; Kuzma, 2019).

In the reef context, one may need to determine the relative advantage of using a (perceived) risky technology to solve reef degradation (i.e., gene-based heat-tolerant coral). People must weigh up the innovation's impact on sociocultural values and economic benefit, from their own perspective. If heat-tolerant coral were to replace damaged parts of the GBR, would tourists continue to visit the reef as a "natural wonder" and would it still hold the same national heritage value?

\section{Present Study}

The present study examines public perceptions toward the genetic engineering of coral, using synthetic biology to combat the effects of rising sea temperatures on these organisms. The study explores a range of potential influences on participants' willingness to support the technology's development and intended willingness to visit parts of the reef, assuming genetically engineered coral were to be introduced. It was hypothesized that threat severity, response efficacy, perceived costs (negative relationship) and perceived benefits would significantly influence support for a synbio-based heat tolerant coral. It was further hypothesized that support for technology development would positvely influence willingness to visit the reef (containing genetically engineered coral). In the present study, "threat" was operationalized as coral reef loss/degradation and the recommended "response" was genetically engineered heattolerant coral. Moreover, since stated acceptance or support for technologies is likely to be influenced by the quality and quantity of information presented (Costa-Font et al., 2008), it is argued that a more engaging explanation of the technology that aligns with how humans process and understand information (e.g., through visual media) is needed. Therefore, to convey complex reef restoration technology (i.e., genetically engineered coral), the authors purposefully designed visually appealing, engaging, and simple-to-understand technology "storyboards."

\section{MATERIALS AND METHODS}

\section{Participants}

One thousand one hundred and forty-eight $(N=1,148)$ members of the Australian public participated in this study. The sample was representative of the national population across age (years: 18$24=13 \%, 25-34=16 \%, 35-44=14 \%, 45-54=19 \%, 55-64=17 \%$, $65+=21 \%)$ and gender (53\% female, $47 \%$ male) (Australian Bureau of Statistics, 2016). Approximately 3\% of the sample were 
of Aboriginal and Torres Strait Islander origin, which mirrors the general Australia population. Education (Mode $=$ Bachelor's degree; 28\%) and household income (Mode $=\$ 50,000-\$ 99,999$, 28\%) were also measured. Most participants (63\%) were employed, working full-time (43\%).

\section{Measures}

The survey comprised a subset of items designed to measure key factors likely to influence support for genetically engineered coral and willingness to visit the reef after the hypothetical deployment of genetically engineered coral. To minimize the length of the survey and reduce response fatigue, single item measures were utilized for some variables, with high face validity. The use of single-item measures has been recommended for variables that have a simple, clear object and a single attribute (Bergkvist and Rossiter, 2007).

Threat severity was measured by asking participants "To what extent do you think coral reef loss is a problem?" $(1=$ not a problem at all to $5=$ a very big problem). In this study, threat was defined as "significant coral loss in the Great Barrier Reef." This measure was derived from original protection motivation theory and previous research in environmental science using protection motivation framing (Grothmann and Reusswig, 2006; Martin et al., 2007; Mankad et al., 2019).

Implicit threat vulnerability was measured by asking participants "Using the sliding scale below, please indicate when you think it would be most appropriate to introduce genetically modified coral into the Great Barrier Reef" ( $0 \%$ no reef remaining to $100 \%$ reef remaining, in $10 \%$ increments). This measure was developed to identify at which point participants were willing to bear the perceived risks of genetically engineered coral and support intervention. Higher scores, by virtue of suggesting that genetically modified coral should be introduced sooner (when there is more reef remaining) rather than later (when there is less reef remaining), may implicitly reflect a higher level of perceived vulnerability.

Response efficacy was measured by asking participants "To what extent do you believe that this new technology would help reduce or eliminate coral reef loss?" $(1=$ would not help at all to $5=$ would be very helpful). This item was developed using protection motivation principles (Rogers and Mewborn, 1976; Rogers, 1983), where participants were asked to consider how effective the recommended solution was to the identified threat (significant coral loss).

Perceived costs (risks) were measured using three items: "To what extent would you be concerned about the long-term effects of the technology on humans and animals?", "To what extent would you be concerned about the long-term effects of the technology on the natural environment?" and "To what extent would you be concerned about whether the consequences of the technology can be effectively controlled or managed?" $(1=$ not concerned, $3=$ moderately concerned, $5=$ extremely concerned; and $\alpha=0.92$ ). Items were combined after first checking inter-item consistency and reliability, and an average "perceived costs" score was calculated. This measure operationalized "costs" as perceived psychological losses (e.g., perceived lack of control) or unknowns associated with the technology and its use. In Rogers' (1983) original framing, costs were defined as response costs associated with the recommended threat-reducing behavior or action (i.e., broader than economic costs; Rippetoe and Rogers, 1987; Rainear and Christensen, 2017).

Perceived benefit (relative advantage) was measured with a single item: "I think that this new technology would be better than current methods of protecting the reef from coral loss" $(1=$ strongly disagree to $5=$ strongly agree $)$. This measure was conceptually informed by Rogers' diffusion of innovation model for technology uptake (Valente and Rogers, 1995; Rogers, 2004). This measure was included to acknowledge the importance of "relative advantage" in the uptake of novel behaviors and its strong influence on support for novel technologies in past literature (Pannell et al., 2006; Kuehne et al., 2017).

Support for the technology was the first dependent variable (DV1) in the study, assessed by asking participants: "Overall, based on the information provided and your own general knowledge, to what extent would you support the development of this technology?" ( $1=$ would not support to $5=$ would strongly support). This was a measure of attitudinal intention, aligned with Rogers (1983) protection motivation framing.

Willingness to visit the reef was the second dependent variable (DV2) in the study, measured by asking participants: "To what extent would you be willing to visit parts of the Great Barrier Reef where genetically engineered coral has been introduced?" $(1=$ not willing to $5=$ very willing). This item was included to measure a more defined behavioral intention to engage with the proposed technology, beyond stated support.

\section{Procedure}

Participants were recruited via an external third-party research agency, with each participant receiving a small token for participation. To participate in the study, respondents were required to be an Australian resident and over the age of 18 years.

A standard introductory email invitation was sent to potential participants take part in an online survey. Upon clicking the survey link, an introductory statement was displayed explaining the general purpose of the study and inviting participants to complete the survey. Participants were then randomly assigned into one of seven different technological scenarios, of which genetically engineering heat-tolerant coral was one ${ }^{1}$. Those who agreed to participate provided consent by ticking a checkbox and continuing with the survey. Initial demographic information (gender, age, postcode, and state of residence) was collected to achieve quotas, thereby ensuring a representative sample of the Australian population on age, gender and location.

At the beginning of the survey, participants were provided with a general definition of synthetic biology, describing synbio as a new field of research bringing together genetics, chemistry and engineering, allowing scientists to design and build new biological organisms that could potentially perform new functions. The

\footnotetext{
${ }^{1}$ This study forms part of a larger suite of projects exploring public responses to a range of synthetic biology technologies. Other technology scenarios examined: gene marking of male chickens, gene editing of natural fibers, gene editing of invasive pests, genetically engineering a pseudo-organism, gene editing of diseasesusceptible mosquitos, and gene editing of endangered species; data for these are in preparation.
} 
introductory definition also stated that synbio could use DNA to create new characteristics, or remove certain functions, in plants, animals and other organisms (e.g., bacteria, fungi, and algae); a pop-up box with a definition for DNA was also made available for participants, if needed.

After the synbio definition was provided to participants, a visual storyboard was presented, describing the technological innovation to participants. This storyboard provided textual and visual information about the genetic engineering of coral $^{2}$. Participants were then asked to complete a series of questions. Further demographic information was requested at the end of the survey (e.g., education and employment status).

The survey took, on average, 15 minutes to complete. The study was reviewed and approved by the relevant Social and Interdisciplinary Human Research Ethics Committee.

\section{Technology Storyboard}

A key part of this project, and an extension of previous literature, was the presentation of a problem-solution framing to convey information about the synthetic biology technology and how it could be used to enhance thermal tolerance in coral. The information presented in the technological storyboards (Figure 1) was sequenced as follows:

- An introduction to the problem.

- Current methods of managing the problem.

- A novel synthetic biology solution for the problem.

It was determined, through consultation with biophysical scientists and broader considerations of the potential for undue psychological influence, that specific risks would not be included as part of the technology storyboards (O'Neill and NicholsonCole, 2009). While it is unlikely that this technology is riskfree, uncertainty in regard to defining and quantifying specific risks at this point in technology development was considered presumptive. The potential for inaccurate risks to be portrayed clouding participant interpretations of the information provided was high. Methodologically, the priority was to examine the influence of emergent underlying risk perceptions, rather than the influence of one's reaction to stated risk.

The technological storyboards were pilot-tested with members of the general public in focus group discussions $(n=31)$. Additional comprehension checks were built into the survey to ensure that the information conveyed in the technological storyboard was being understood by participants. The average comprehension score was 2.25 out of a maximum of 3 correct answers, with a standard deviation $(S D)=0.91$ and a range $0-$ 3. These values indicate that, in general, people understood the information conveyed in the storyboard.

\section{Analytic Approach}

There were two dependent variables in the study: (1) intention to support the development of genetically engineered coral;

\footnotetext{
${ }^{2}$ A small experiment was embedded into the original storyboard design, providing a sub-sample of participants with additional information on technology "regulation" and "public engagement." However, the experiment was found to have a n.s., effect on all responses; therefore, it is not explored further in this study.
}

and (2) willingness to visit the reef after the introduction of genetically engineered coral. Descriptive statistics were calculated to examine the distribution of psychological correlates and support variables throughout the population; in subsequent statistical reporting, mean is denoted by $M$ and standard deviation is denoted by $S D$. A follow-up $t$-test was used to determine whether means significantly differed between support for development of the technology and willingness to visit the reef. A $t$-test measures whether the means of two groups or variables are significantly different to each other, at a conventional twotailed probability level $(p<0.05)$. The degrees of freedom are also reported as they help to determine the statistical significance.

Path analysis was used to estimate the relationships among the observed variables, and to reveal the relative effects of each variable in explaining support measures. Unlike a structural equation model, only the structural relationships among the observed variables are modeled in a path model. There were no latent variables and no measurement model. The path analysis afforded the ability to assess indirect as well as total effects (i.e., combined direct and indirect effects). Direct effects refer to the relationship between two variables without any intervening variables. Indirect effects reflect the effect of a variables on a dependent variable via one or more intervening variables. The chi-square, CFI, TLI, RMSEA, and SRMR ${ }^{3}$ were used to evaluate model fit. Modification indices (MI) are reported to indicate the improvement to model fit if certain changes are made to the model. The modification index value reflects the chi-square value, with 1 degree of freedom, by which the model fit would improve if a particular path was added.

\section{RESULTS}

\section{Psychological Correlates of Support for Genetically Engineering Coral}

Descriptive analyses and correlations between factors were calculated to evaluate participants' level of perceived threat, associated perceptions of a synthetic biology solution in addressing the threat, and intentions to support the development of a genetic solution for coral degradation. The study examined not only support for development of genetically engineered coral, but also willingness to interact with the technology directly, measured using behavioral intention to visit regions where genetically engineered coral had (hypothetically) been introduced. A table of mean scores is provided in Table 1; however, note that implicit threat vulnerability is not presented in this table due to its unique measurement scale. On average, participants believed the threat of significant coral loss in the GBR was severe. Perceptions of technology efficacy, perceived costs (risks) and relative advantage were moderate to high. The distribution indicated that extremely high and low responses were less prevalent, and most people scored around, or slightly higher than, the mid-point of the scale.

\footnotetext{
${ }^{3}$ The listed statistics are fit indices estimated in statistical path modelling to evaluate model fit: comparative fit index (CFI), Tucker-Lewis index (TLI), root mean square error of approximation (RMSEA), standardized root mean squared residual (SRMR).
} 
TABLE 1 | Mean scores for independent and dependent variables in the study (excluding implicit threat vulnerability), ranging from 1 - 5, with higher scores reflecting stronger responses.

\begin{tabular}{|c|c|c|c|c|c|c|c|}
\hline \multirow[t]{2}{*}{ Factor } & \multirow[t]{2}{*}{$N$} & \multirow[t]{2}{*}{ Mean } & \multirow[t]{2}{*}{$S D$} & \multicolumn{2}{|c|}{ Skewness $^{a}$} & \multicolumn{2}{|c|}{ Kurtosis ${ }^{a}$} \\
\hline & & & & Statistic & Std. error & Statistic & Std. error \\
\hline Threat severity & 1148 & 4.23 & 0.95 & -1.18 & 0.07 & 0.88 & 0.14 \\
\hline Response efficacy & 1148 & 3.61 & 0.90 & -0.37 & 0.07 & 0.09 & 0.14 \\
\hline Perceived costs (risks) & 1148 & 3.52 & 0.96 & -0.15 & 0.07 & -0.42 & 0.14 \\
\hline Perceived benefits (relative advantage) & 1148 & 3.54 & 0.93 & -0.41 & 0.07 & 0.29 & 0.14 \\
\hline Intention to support (DV) & 1148 & 3.69 & 1.04 & -0.57 & 0.07 & -0.07 & 0.14 \\
\hline Willingness to visit reef post-gene tech implementation (DV) & 1148 & 3.79 & 1.13 & -0.72 & 0.07 & -0.15 & 0.14 \\
\hline
\end{tabular}

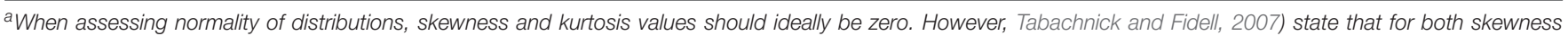

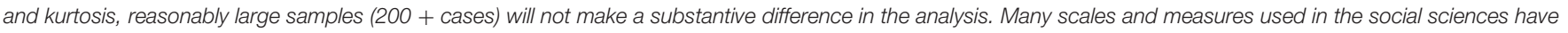
scores that are skewed, and this reflects the nature of the underlying constructs being measured rather than indicating a problem with the scale (Pallant, 2007).

TABLE 2 | Correlation table showing the relationships between all independent and dependent variables in the study.

\begin{tabular}{|c|c|c|c|c|c|c|c|}
\hline Variables & $\begin{array}{c}\text { Threat } \\
\text { severity }\end{array}$ & $\begin{array}{l}\text { Implicit threat } \\
\text { vulnerability }\end{array}$ & $\begin{array}{c}\text { Efficacy of } \\
\text { tech }\end{array}$ & $\begin{array}{c}\text { Perceived } \\
\text { costs (risks) }\end{array}$ & $\begin{array}{c}\text { Perceived } \\
\text { benefits } \\
\text { (relative } \\
\text { advantage) }\end{array}$ & $\begin{array}{l}\text { Intention to } \\
\text { support (DV1) }\end{array}$ & $\begin{array}{l}\text { Willingness to } \\
\text { visit reef (DV2) }\end{array}$ \\
\hline Threat severity & 1 & $0.11^{\star *}$ & $0.37^{\star \star}$ & $0.17^{\star \star}$ & $0.33^{\star \star}$ & $0.30^{\star \star}$ & $0.39^{\star \star}$ \\
\hline Implicit threat vulnerability & $0.11^{* *}$ & 1 & $0.35^{\star *}$ & $-0.15^{\star \star}$ & $0.35^{\star \star}$ & $0.35^{\star *}$ & $0.19^{\star *}$ \\
\hline Efficacy of tech & $0.37^{\star *}$ & $0.35^{\star \star}$ & 1 & $-0.16^{\star \star}$ & $0.64^{\star \star}$ & $0.61^{\star \star}$ & $0.42^{\star *}$ \\
\hline Perceived costs (risks) & $0.17^{\star \star}$ & $-0.15^{\star \star}$ & $-0.16^{\star \star}$ & 1 & $-0.16^{\star \star}$ & $-0.23^{\star \star}$ & -0.04 \\
\hline Perceived benefits (relative advantage) & $0.33^{\star *}$ & $0.35^{\star *}$ & $0.64^{\star *}$ & $-0.16^{\star *}$ & 1 & $0.64^{\star *}$ & $0.41^{* *}$ \\
\hline Intention to support (DV1) & $0.30^{\star *}$ & $0.35^{\star *}$ & $0.61^{* *}$ & $-0.23^{\star \star}$ & $0.64^{\star \star}$ & 1 & $0.48^{\star \star}$ \\
\hline Willingness to visit reef (DV2) & $0.39^{\star \star}$ & $0.19^{\star *}$ & $0.42^{\star \star}$ & -0.04 & $0.41^{\star \star}$ & $0.48^{\star \star}$ & 1 \\
\hline
\end{tabular}

${ }^{* *}$ Correlation is significant at the 0.01 level (two-tailed).

The correlation table (Table 2) demonstrates the relationships among the variables included in this analysis, with significant relationship between all variables, suggesting an appropriate mix of variables. Understandably, there was a strong positive correlation between perceived efficacy of the technology and perceived benefits (relative advantage). The more people believed that genetically engineered coral would be effective in mitigating significant coral loss, the more strongly they believed the genetic solution would be better than current methods of protecting the reef from coral loss. There was also a strong correlation between perceived efficacy of the technology and perceived benefits (relative advantage) with intention to support.

Overall, as illustrated in Table 1, support for the development of genetically engineered coral as a potential solution to significant coral loss in the GBR was moderate to high, with similarly moderate to high levels of willingness to visit parts of the GBR where genetically engineered coral had been (hypothetically) introduced. The positive correlation between the two dependent variables was significant, indicating a moderate positive relationship (Table 2). The correlation table further shows that there is no multicollinearity and relationships are generally present in the hypothesized direction. Interestingly, there was no significant correlation between perceived costs (risks) and willingness to visit the reef, indicating the absence of a direct relationship between those variables.

\section{Implicit Threat Vulnerability}

An important consideration in the acceptance of genetically engineered coral was one's belief regarding if, and when, the synbio technology should be introduced. While not an outright measure of threat vulnerability, this variable was included to reflect a cognitive trade-off between perceived threat severity and perceived vulnerability (how likely is it that the threat will eventuate).

Figure 2 shows that participants were most keen to implement a genetically engineered coral solution when there was between $50-70 \%$ of reef remaining intact. Approximately one in ten people were not comfortable with genetically modified coral being introduced at all.

\section{Intention to Support Genetically Engineered Coral}

A key dependent variable in the present analysis was stated support for the development of genetically engineered coral, as a possible solution to coral degradation. Descriptive analyses showed that, in general, participants were moderately to strongly supportive of technology development. As Figure 3 illustrates, responses favored the higher end of the stated support scale, with a mean $(M)=3.69(S D=1.04)$.

\section{Willingness to Visit the Reef After Introduction of Genetically Engineered Coral}

The second dependent variable examined in this study was one's stated willingness to visit the GBR should genetically 


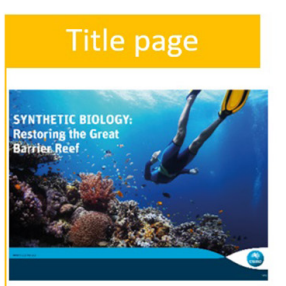

Synthetic Biology:

Genetically

engineering coral

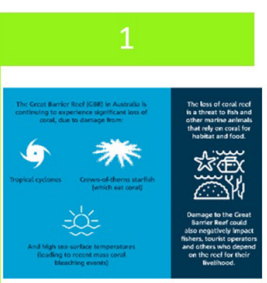

Statement of the problem (threat):

Significant coral loss in the Great Barrier Reef

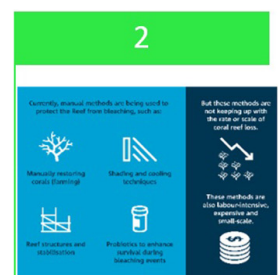

Current solutions addressing the problem

Associated limitations

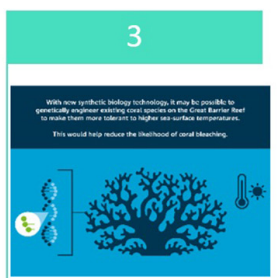

Novel synthetic biology solution Presented as a 'possible' future solution

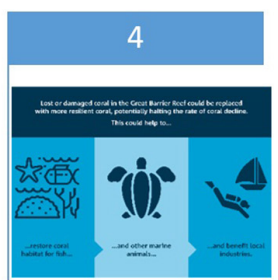

Possible benefits of synthetic biology solution

Broader benefits than just coral restoration

FIGURE 1 | Technology storyboard for genetically engineering coral; this storyboard was the "technology" reference for all responses within the survey.

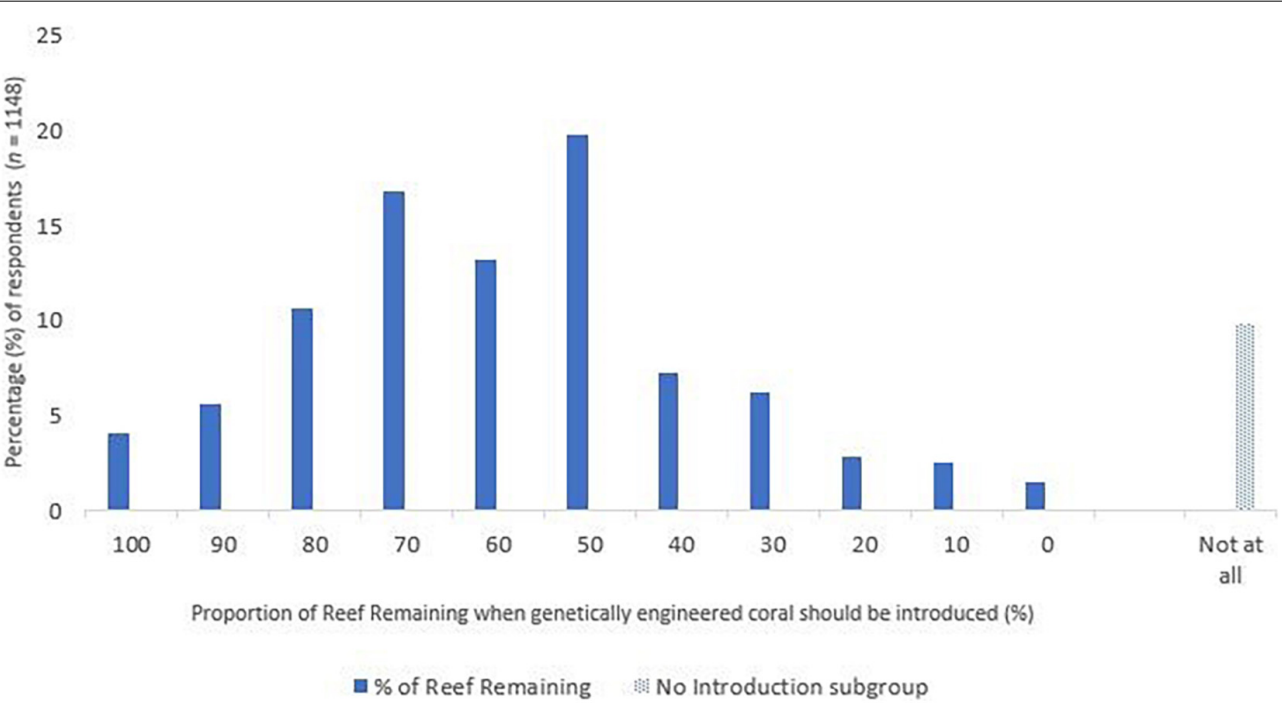

FIGURE 2 | Distribution of participant responses ( $N=1148)$ when asked to determine when it would be most appropriate to introduce genetically modified coral into the Great Barrier Reef based on the percentage of remaining reef (i.e., level of reef degradation). The "No Introduction" subgroup ( $n=113$ ) represents those who were not comfortable with genetically modified coral being introduced at all.

engineered coral be implemented as a solution in the reef. This variable was an implicit measure of support, which targeted behavioral intention. Figure 3 shows that participants expressed moderate to strong behavioral intentions to visit the reef after the implementation of genetically engineered coral. A follow-up $t$-test found that the average score for willingness to visit the reef $(M=3.79, S D=1.13)$ was significantly higher than intention to support technology development $(M=3.69, S D=1.04$; $\left.t_{1147}=3.32, p=0.001\right)$.

\section{Path Model}

As shown in Table 3, the hypothesized path model did not fit the data well. A review of the modification indices suggested the addition of direct relationships between: threat severity and willingness to visit reef $(\mathrm{MI}=80.09, p=0.000)$, efficacy of technology and willingness to visit reef $(\mathrm{MI}=36.41, p=0.000)$, and perceived benefits (relative advantage) and willingness to visit reef $(\mathrm{MI}=29.55, p=0.000)$. Once these three additional direct paths were included, the fit of the model improved and revealed a good fit to the data. Thus, a partially mediated model was accepted as the final model. This model is shown in Figure 4. All associations amongst the variables were in the predicted direction and a significant amount of variance was explained in the dependent variable and mediator. That is, $24 \%$ of the variability in willingness to visit reef and $40 \%$ of the variability in intention to support development of the technology was explained by the explanatory variables.

\section{DISCUSSION}

Global advances in synthetic biology (synbio) has the potential to accelerate and scale up selective breeding of heat-tolerant 

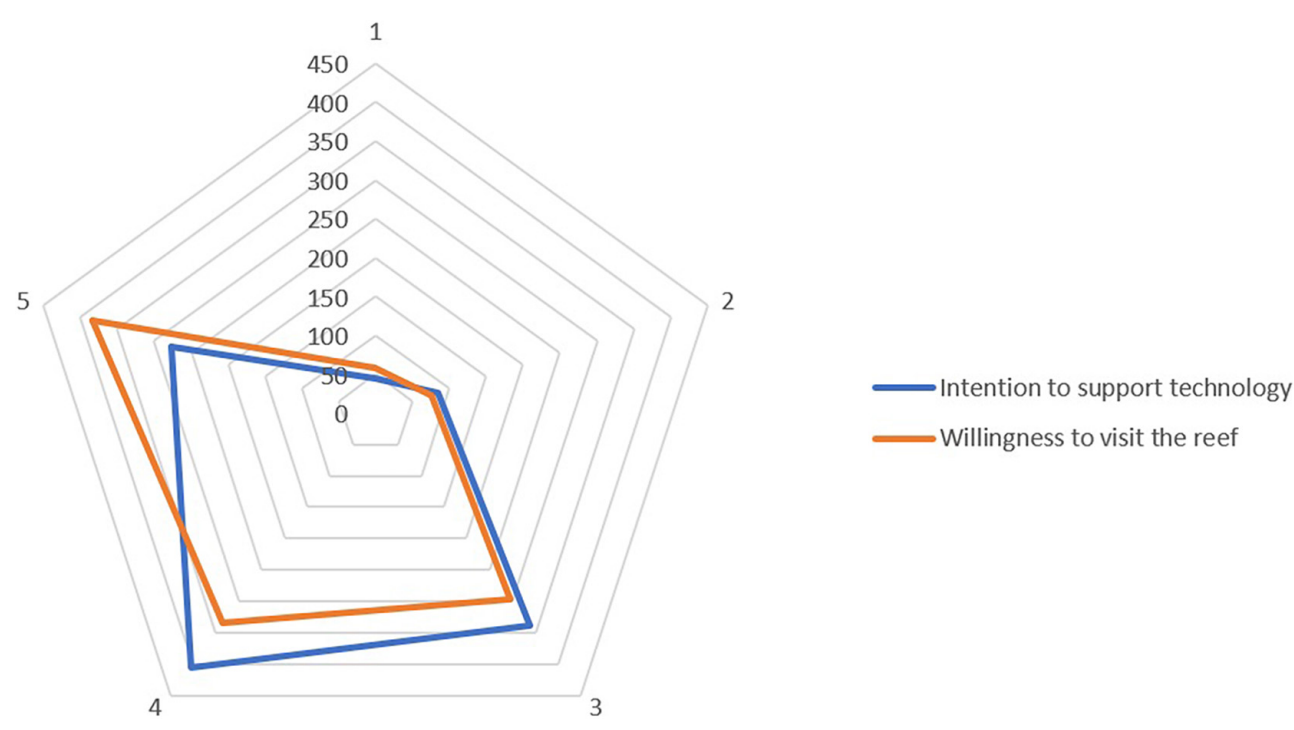

Willingness to visit the reef

FIGURE 3 | Frequency distributions for the two dependent variables: "Intention to support development of technology" and "Willingness to visit the reef after introduction of genetically engineered coral." Note that "technology" refers to genetically engineered coral; responses were made using a 5-point scale where higher scores indicated greater intention and willingness.

TABLE 3 | Fit statistics for the hypothesized and final path models.

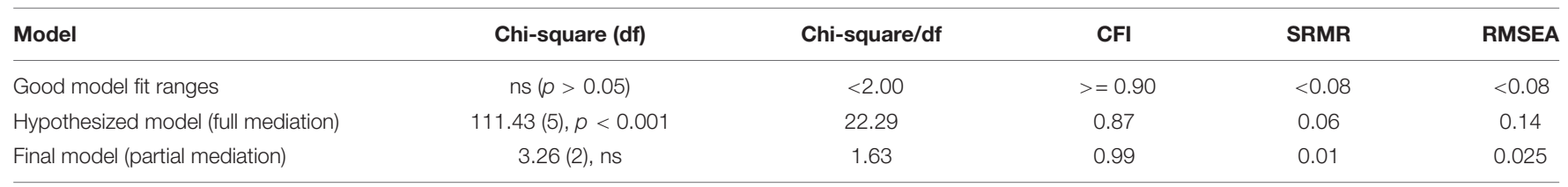

coral. This can offer a longer-term gene-based conservation solution to mitigate the damaging effects of coral bleaching (Bay et al., 2019). The present research adopts a behavioral science approach to understand public attitudes and perceptions toward the development of, and possible future implementation of, novel synbio solutions in the reef. The data identifies drivers of technology support and engagement. Results show that: (a) participants generally agreed that genetically engineered coral could address the identified threat; (b) there was a perceived benefit in implementing the gene technology and a relative advantage over other methods of addressing coral loss; and (c) there were also perceived costs (risks) associated with technology implementation. However, this lack of opposition is conditional and many participants also expressed parallel concerns about the long-term impacts of genetically engineered coral on humans, animals, and the natural environment, and whether the consequences of the technology could be effectively managed. The results also suggest that stated support for technology development notwithstanding, participants were more willing to engage with the technology were it to be implemented in the GBR as a solution to coral degradation.

\section{Technology Benefits and Effectiveness Are More Important Than Potential Risks}

Participants' support for genetically engineered coral was primarily influenced by: (a) their belief that a synbio solution significantly superseded current methods of coral loss prevention; and (b) the technology's perceived effectiveness in mitigating the coral loss problem. Pankratz et al. (2002) argue that perceived advantage of a novel technological solution is related to increased uptake of an innovation, but is especially useful when assessing policy adoption of an intervention. Although this study examined perceived benefit at the individual level, Pankratz et al. (2002) further suggest that at the organizational level, if a technology is perceived as being superior to its predecessor, there is greater likelihood of securing funding and support. Therefore, it may be useful for future end users of the technology (e.g., marine park managers) to know that innovative synbio coral technology is perceived as advantageous by the Australian public and that this belief is also linked with higher technology support and a greater willingness to visit the reef post-intervention.

Results from this study also demonstrate the cultural value and importance of the GBR amongst the sample. While perceptions of threat severity were not influential in predicting support for the synbio technology, people still believed coral reef loss to be a severe threat in Australia and believed it was necessary to implement a viable solution sooner rather than later. It is also interesting to note that when asked about perceived costs and benefits, scores hovered slightly above the mid-point of the scale ( 23.5 on a $1-5$ scale) for both variables; that is, respondents, on average, were a little more than moderately concerned about the potential risks while still slightly agreeing that the technology 


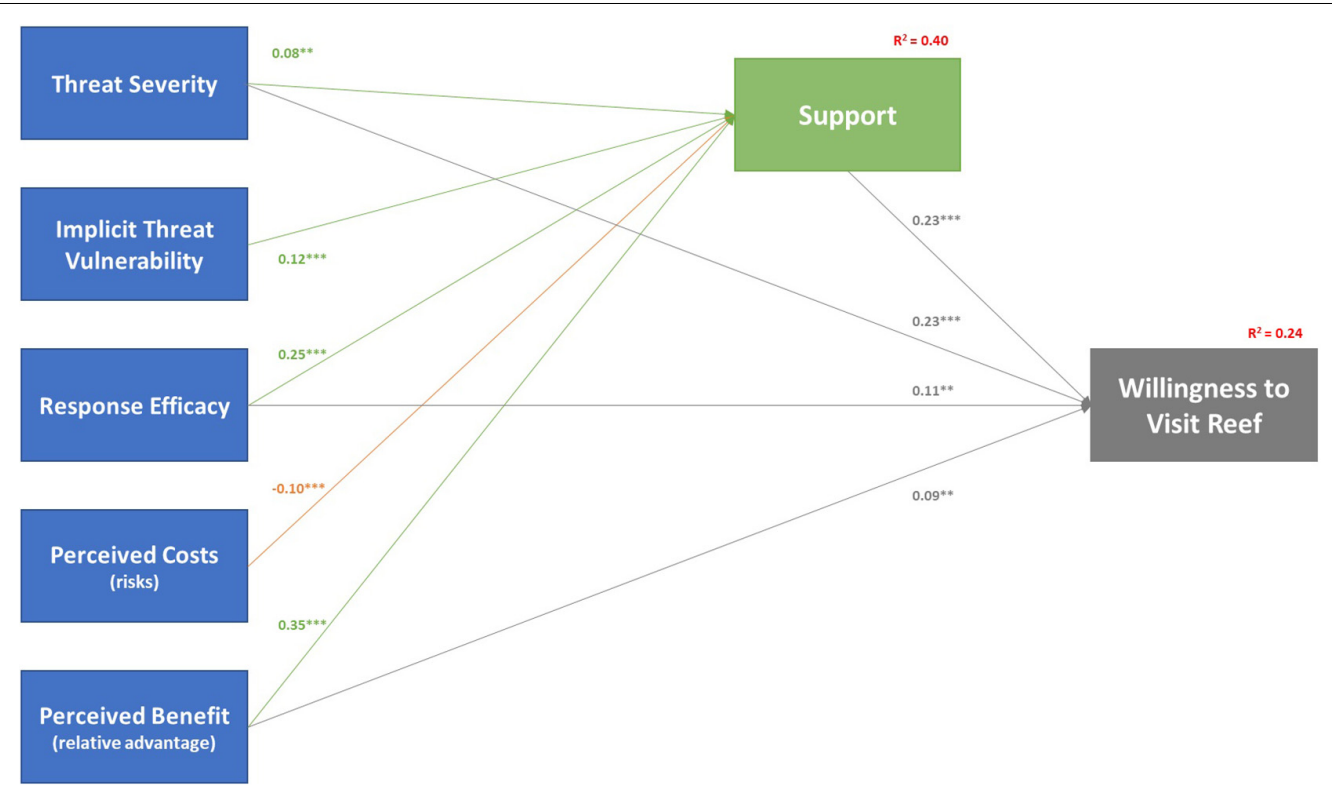

FIGURE 4 | Partially mediated path model $\left(R^{2}=0.46\right)$, showing direct and indirect effects of psychological correlates (blue boxes) on attitudinal intention to support the technology (green box) and behavioral willingness to visit the reef (gray box). Green arrows and blue arrows represent a direct positive relationships between psychological correlates and the dependent variables; orange arrow represents a direct negative relationship between psychological correlates and "intention to support"; and the gray arrow represents a mediated relationship between the dependent variables. ${ }^{\star \star}$ refers to significance at the $p<0.01$ and ${ }^{\star \star \star}$ refers to significance at the $p<0.001$ level.

would be better than current methods. It is possible that people may hold equally strong, but divergent, views on the need for a "radical" solution to save a dying reef while also experiencing an inherent precaution toward the unknown consequences of this technology.

This high level of uncertainty with respect to the technology may also be a by-product of the fact that this study's presentation of the technology did not explicitly communicate any risks and instead focused on explaining the problem situation and potential benefits of the proposed technological solution. While the reasoning for this was to allow individuals to elicit their own perception of risk rather than introducing hypothetical risks or priming, this approach may have potentially biased responses in favor of the synbio/genetic solution presented. However, the authors argue that this method still allowed for a robust examination of public perceptions of the proposed technology, particularly as the path model found good discrimination and fit between the causal variables in predicting support for genetically engineered coral.

\section{Protective Sentiment Toward the Reef and Support for a Novel Solution}

The present results are consistent with prior research that suggests perceived threat could raise a sense of value and protective sentiments toward the reef and simultaneously motivate collective action to protect and conserve the reef (Curnock et al., 2019). Additionally, prior research has found that some tourists travel to the GBR mainly because they wish to see the reef before it is too late (Piggott-McKellar and McNamara,
2017), highlighting the important motivational role of threat perceptions. The study shows that while perceived threat severity (i.e., the belief that coral reef loss is a problem) was not a strong attitudinal driver of technology support, it was the equal strongest predictor of willingness to visit the reef along with technology support.

The importance of protecting the reef is further reflected in participants' stated threshold for synbio intervention in the reef (implicit threat vulnerability). Many felt that the right time to introduce a genetic solution to coral reef loss was when approximately $50-70 \%$ (which in fact corresponds to $25-35 \%$ in absolute terms) of coral reef was remaining in the GBR. Similarly, one's desire to visit the reef post-intervention was also higher when they also believed that coral reef loss was a problem in the GBR. In reality, coral cover is not $100 \%$ even on healthy reefs. Density of cover depends on many factors (e.g., water temperature, location, and human activities; Bruno et al., 2009). Early published quantitative surveys of coral cover cite baseline at around 50\% (Bruno et al., 2014; Eddy et al., 2018). Eddy et al. (2018) report the earliest quantitative estimate of coral cover in some parts of the GBR was as low as $28 \%$ in 1985 . Thus, in "real" terms, if coral cover is scaled more absolutely as a $0-50 \%$ scale (based on early published quantitative survey values), the "real" threshold point at which participants were most supportive of implementing a genetically engineered coral solution was between 25 and $5 \%$ of coral cover remaining. Current estimates reported by the Australian Institute of Marine Science have cited the range of coral cover across the GBR at between 10 and $30 \%$ in 2018/2019 (Australian Institute of Marine Science, 2019), significantly below participants' stated threshold for a genetic 
solution. One could argue that if a synthetic biology solution was to be implemented on the reef today, it might be met with less public resistance than, perhaps, 20 years ago when coral reef cover in the GBR was significantly higher. The inference here is that threat perceptions raise protective sentiments toward the reef to the extent that they may catalyze actions to save it (Curnock et al., 2019).

\section{Response Costs and Mental Trade-Offs}

The measure of implicit threat vulnerability in this study enabled the detection of a reef loss threshold for technology implementation amongst participants. It provides some understanding of the point at which people were willing to make a decisional trade-off between perceived risks of the technology and perceived benefits. To understand this further, the study also examined perceptions of response costs or risks associated with the introduction of genetically engineered coral in the GBR, in addition to the perceived benefits of the technology. Original protection motivation framing defined costs as "any 'costs' of adopting the recommended preventive response" (Rogers, 1983, p. 169), including mental difficulty and complexity in decision-making, which requires a significant cognitive cost or load. The measurement of perceived costs in the present study asked participants to weigh up their concerns about long-term effects of genetically engineered coral on humans, animals, and the natural environment. Participants were also asked the extent to which they were concerned that the consequences could be effectively controlled or managed. Although higher perceived costs did predict lower support for the development of synbio coral, there was no relationship between perceived costs (risks) and willingness to engage with the technology in situ. This suggests a potential distinction made by participants between initial support for the development of synbio coral versus their behavioral intention to engage with the technology should it be implemented.

\section{Willingness to Visit the Reef}

While participants were at least moderately supportive of developing a genetic solution for restoring and protecting coral loss in the GBR, it was interesting to see a higher stated willingness to visit areas of the GBR where genetically engineered coral may be introduced. This suggests a significant conceptual distinction between attitudinal support for the technology and a behavioral willingness toward engaging with the reef postintervention. Further, it also exemplifies that individuals are employing mental trade-offs when deciding and contextualizing their support for the technology development. An inherent acknowledgment exists that this conservation technology comes with uncertainty and potential risks, however, the value of the reef is such that people would be willing to tolerate some risk and still be more likely than not to visit parts of the GBR where genetically engineered coral has been introduced. An explanation of this position may be that although people vary on their level of support or acceptance for a synbio solution to the coral loss problem, other factors can independently influence one's behavioral interaction with the technology, such as sociocultural values associated with the reef (Piggott-McKellar and McNamara,
2017; Curnock et al., 2019). The national importance of the GBR and associated public protective sentiment may, thus, encourage public engagement with an uncertain technology more readily than an arena where the perceived need is lower. However, in equal measure, this may also mean greater public scrutiny around technology efficacy and the promise of delivery.

\section{Limitations}

This study provides a preliminary view of how the public might respond to the introduction of genetically engineered coral. While an effort was made to explain the technology by using both visual diagrams and simple text (in the form of a storyboard), it is recognized that the presentation of information was simplistic and survey research methods carry with them inherent limitations (see Podsakoff et al., 2003; Podsakoff et al., 2012 for a discussion of common method variance). However, the main limitation of the current research that must be acknowledged is the lack of targeted sampling of Aboriginal and Torres Strait Islander perspectives toward the use of genetically engineered coral in the GBR specifically. Along the GBR coast, Aboriginal and Torres Strait Islander communities are the Traditional custodians of the GBR and any changes to the delicate balance of the GBR ecosystem would impact this group significantly. Thus, while these results are meaningful and comprise an Aboriginal and Torres Strait Islander sample that is proportional to that of the broader Australian population, it is important to acknowledge that the results reflect a bias toward non-Indigenous perspectives of the GBR. Similarly, the current research did not specifically target residents living in the GBR region. Long-term GBR locals like Aboriginal and Torres Strait Islander communities living along the GBR coast - may be sensitive to changes to the GBR, especially if they rely on the reef for their livelihood (e.g., tourism operators and fishers). Future research may therefore seek to undertake a more place-based analysis of public perceptions by surveying residents living in the GBR region.

\section{Conclusion}

The perceived need for a viable solution for coral reef loss in Australia is clearly high, and the inextricable link that Australians have with the World Heritage site make it not only an ideal candidate for novel solutions, but also one fraught with incredibly complex social institutions (Lane and Robinson, 2009; Curnock et al., 2019; Westoby and McNamara, 2019). This study demonstrates that public decision making about acceptance of synthetic biology technologies is predicated on multiple and interrelated factors about the technology's efficacy and intended benefits, rather than a set of static beliefs and values around risk. This suggests that, all things considered, the public are open to learning about synthetic biology technology for reef conservation and are willing to consider it as a potential solution to a defined problem. If this synthetic biology solution continues to be developed and emerges as a viable solution for reef restoration and conservation, it is recommended that engagement with the public focus more on technology efficacy and intended benefits. Developers should also seek end user feedback for areas of technology uncertainty and risk, to integrate into all stages of research development and plans for implementation. 
This research also makes a novel contribution to the broader literature on public engagement with science through the creation of a storyboard to communicate complex science. The authors contend that without the presentation of the storyboard (e.g., the use of a textual description alone), it would have been difficult for many participants to form an understanding and appraisal of the complex technology. These findings provide the science communication and research communities with valuable insights to inform future public messaging campaigns.

\section{DATA AVAILABILITY STATEMENT}

The raw data supporting the conclusions of this article will be made available by the authors, without undue reservation.

\section{ETHICS STATEMENT}

The studies involving human participants were reviewed and approved by CSIRO Social and Interdisciplinary Science Human Research Ethics Committee. The participants provided their written informed consent to participate in this study.

\section{AUTHOR CONTRIBUTIONS}

AM: conceptualization, data curation, formal analysis, funding acquisition, investigation, methodology, project administration, resource visualization, supervision, validation, roles and

\section{REFERENCES}

Australian Bureau of Statistics (2016). 2008.0 Census of Population and Housing: Nature and Content. Available online at: https://www.abs.gov.au/ausstats/abs@ .nsf/Lookup/bySubject/2008.0 2016 MainFeatures Topicreleaseschedule 140 (accessed May 14, 2020).

Australian Institute of Marine Science (2019). Long-Term Reef Monitoring Program - Annual Summary Report on Coral Reef Condition for 2018/19. Available online at: https://www.aims.gov.au/reef-monitoring/gbr-condition-summary2018-2019 (accessed May 14, 2020).

Barnett, J., Cooper, H., and Senior, V. (2007). Belief in public efficacy, trust, and attitudes toward modern genetic science. Risk Anal. 27, 921-933. doi: 10.1111/ j.1539-6924.2007.00932.x

Bay, L. K., Rocker, M., Boström-Einarsson, L., Babcock, R., Buerger, P., Cleves, P., et al. (2019). Reef Restoration and Adaptation Program: Intervention Technical Summary. A Report Provided to the Australian Government by the Reef Restoration and Adaptation Program. Townsville, QLD: Australian Institute of Marine Science (AIMS).

Bergkvist, L., and Rossiter, J. R. (2007). The predictive validity of multiple-item versus single-item measures of the same constructs. J. Mark. Res. 44, 175-184. doi: $10.1509 / j \mathrm{mkr} .44 .2 .175$

Blunt, E. A. (2012). Protection Motivation Theory and Consumer Willingness-toPay in the Case of Post-Harvest Processed Gulf Oysters. Master's thesis. College Station, TX: Texas A\&M University.

Bruno, J. F., Precht, W. F., Vroom, P. S., and Aronson, R. B. (2014). Coral reef baselines: how much macroalgae is natural? Mar. Pollut. Bull. 80, 24-29.

Bruno, J. F., Sweatman, H., Precht, W. F., Selig, E. R., and Schutte, V. G. W. (2009). Assessing evidence of phase shifts from coral to macroalgal dominance on coral reefs. Ecology 90, 1478-1484. doi: 10.1890/08-1781.1

Burke, L., Reytar, K., Spalding, M., and Perry, A. (2011). Reefs at Risk: Revisited. Washington, DC: World Resources Institute. writing-original draft, writing-review, and editing. EH: conceptualization, data curation, formal analysis, investigation, methodology, project administration, resource visualization, validation, roles and writing - original draft, writing - review, and editing. LC: conceptualization, resource visualization, writing - original draft, writing - review, and editing. All authors contributed to the article and approved the submitted version.

\section{FUNDING}

This research was funded by the Commonwealth Scientific and Industrial Research Organization (CSIRO).

\section{ACKNOWLEDGMENTS}

The authors would like to acknowledge the assistance of CSIRO Synthetic Biology Future Science Platform biotechnology scientists for assisting with storyboard development, in particular Patrick Buerger and Owain Edwards, for their generosity in reviewing earlier versions of this manuscript.

\section{SUPPLEMENTARY MATERIAL}

The Supplementary Material for this article can be found online at: https://www.frontiersin.org/articles/10.3389/fmars. 2021.710641/full\#supplementary-material

Costa-Font, M., Gil, J. M., and Traill, W. B. (2008). Consumer acceptance, valuation of and attitudes towards genetically modified food: review and implications for food policy. Food Policy 33, 99-111. doi: 10.1016/j.foodpol. 2007.07.002

Curnock, M. I., Marshall, N. A., Thiault, L., Heron, S. F., Hoey, J., Williams, G., et al. (2019). Shifts in tourists' sentiments and climate risk perceptions following mass coral bleaching of the Great Barrier Reef. Nat. Clim. Change 9, 535-541. doi: 10.1038/s41558-019-0504-y

Dobbs, K., Day, J., Skeat, H., Baldwin, J., Molloy, F., McCook, L., et al. (2011). Developing a long-term outlook for the Great Barrier Reef, Australia: a framework for adaptive management reporting underpinning an ecosystembased management approach. Mar. Policy 35, 233-240. doi: 10.1016/j.marpol. 2010.10.007

Eddy, T. D., Cheung, W. W. L., and Bruno, J. F. (2018). Historical baselines of coral cover on tropical reefs as estimated by expert opinion. PeerJ 6:e4308. doi: $10.7717 /$ peerj.4308

Goldberg, J., Marshall, N., Birtles, A., Case, P., Bohensky, E., Curnock, M., et al. (2016). Climate change, the Great Barrier Reef and the response of Australians. Palgrave Commun. 2:15046. doi: 10.1057/palcomms. 2015.46

Great Barrier Reef Marine Park Authority (2019). Outlook Report 2019. Available online at: http://www.gbrmpa.gov.au/our-work/outlook-report-2019 (accessed February 27, 2020).

Great Barrier Reef Marine Park Authority (2020b). GBRMPA - Reeffacts. Available online at: http://www.gbrmpa.gov.au/the-reef/reef-facts (accessed May 14, 2020)

Great Barrier Reef Marine Park Authority (2020a). GBRMPA - Statement: Coral Bleaching on the Great Barrier Reef. Available online at: http://www.gbrmpa.gov.au/news-room/latest-news/latest-news/coralbleaching/2020/statement-coral-bleaching-on-the-great-barrier-reef (accessed May 14, 2020). 
Grothmann, T., and Reusswig, F. (2006). People at risk of flooding: why some residents take precautionary action while others do not. Nat. Hazards 38, 101-120. doi: 10.1007/s11069-005-8604-6

Kirk, N., Kannemeyer, R., Greenaway, A., MacDonald, E., and Stronge, D. (2019). Understanding attitudes on new technologies to manage invasive species. Pac. Conserv. Biol. 26, 35-44. doi: 10.1071/PC18080

Kothe, E. J., Ling, M., North, M., Klas, A., Mullan, B. A., and Novoradovskaya, L. (2019). Protection motivation theory and pro-environmental behaviour: a systematic mapping review. Aust. J. Psychol. 71, 411-432. doi: 10.1111/ajpy. 12271

Kuehne, G., Llewellyn, R., Pannell, D. J., Wilkinson, R., Dolling, P., Ouzman, J., et al. (2017). Predicting farmer uptake of new agricultural practices: a tool for research, extension and policy. Agric. Syst. 156, 115-125. doi: 10.1016/J.AGSY. 2017.06.007

Kuzma, J. (2019). Procedurally robust risk assessment framework for novel genetically engineered organisms and gene drives. Regul. Gov. doi: 10.1111/ rego. 12245

Lane, M. B., and Robinson, C. J. (2009). Institutional complexity and environmental management: the challenge of integration and the promise of large-scale collaboration. Australas. J. Environ. Manage. 16, 16-24. doi: 10. 1080/14486563.2009.9725213

Lewicka, M. (2011). Place attachment: how far have we come in the last 40 years? J. Environ. Psychol. 31, 207-230

Mankad, A., Greenhill, M., Tucker, D., and Tapsuwan, S. (2013). Motivational indicators of protective behaviour in response to urban water shortage threat. J. Hydrol. 491, 100-107.

Mankad, A., Zhang, A., and Curnock, M. (2019). Motivational drivers of action in response to an environmental biosecurity incursion. J. Environ. Manag. 232, 851-857. doi: 10.1016/j.jenvman.2018.11.115

Marquit, J. D. (2008). Threat Perception as a Determinant of Pro- Environmental Behaviors: Public Involvement in Air Pollution Abatement in Cache Valley. Logan, UT: Utah State University.

Marra, M., Pannell, D. J., and Abadi Ghadim, A. (2003). The economics of risk, uncertainty and learning in the adoption of new agricultural technologies: where are we on the learning curve? Agric. Syst. 75, 215-234. doi: 10.1016/ S0308-521X(02)00066-5

Marshall, N., Adger, W. N., Benham, C., Brown, K., Curnock, M. I., Gurney, G. G., et al. (2019). Reef Grief: investigating the relationship between place meanings and place change on the Great Barrier Reef, Australia. Sustain. Sci. 14, 579-587. doi: 10.1007/s11625-019-00666-Z

Marshall, N. A., Thiault, L., Beeden, A., Beeden, R., Benham, C., Curnock, M. I., et al. (2019). Our environmental value orientations influence how we respond to climate change. Front. Psychol. 10:938. doi: 10.3389/fpsyg.2019.00938

Martin, I. M., Bender, H., and Raish, C. (2007). What motivates individuals to protect themselves from risks: the case of wildland fires. Risk Anal. 27, 887-900. doi: 10.1111/j.1539-6924.2007.00930.x

O’Neill, S., and Nicholson-Cole, S. (2009). "Fear won't do it": promoting positive engagement with climate change through visual and iconic representations. Sci. Commun. 30, 355-379. doi: 10.1177/1075547008329201

Pallant, J. (2007). SPSS Survival Manual, 3rd Edn. New York, NY: Open University Press.

Pankratz, M., Hallfors, D., and Cho, H. (2002). Measuring perceptions of innovation adoption: the diffusion of a federal drug prevention policy. Health Educ. Res. 17, 315-326. doi: 10.1093/her/17.3.315

Pannell, D. J., Marshall, G. R., Barr, N., Curtis, A., Vanclay, F., and Wilkinson, R. (2006). Understanding and promoting adoption of conservation practices by rural landholders. Aust. J. Exp. Agric. 46, 1407-1424. doi: 10.1071/EA05037

Piggott-McKellar, A. E., and McNamara, K. E. (2017). Last chance tourism and the Great Barrier Reef. J. Sustain. Tour. 25, 397-415. doi: 10.1080/09669582.2016. 1213849

Podsakoff, P. M., MacKenzie, S. B., Lee, J. Y., and Podsakoff, N. P. (2003). Common method biases in behavioral research: a critical review of the literature and recommended remedies. J. Appl. Psychol. 88, 879-903. doi: 10.1037/0021-9010. 88.5.879

Podsakoff, P. M., MacKenzie, S. B., and Podsakoff, N. P. (2012). Sources of method bias in social science research and recommendations on how to control it. Annu. Rev. Psychol. 63, 539-569. doi: 10.1146/annurev-psych-120710-100452

Rainear, A. M., and Christensen, J. L. (2017). Protection motivation theory as an explanatory framework for proenvironmental behavioral intentions. Commun. Res. Rep. 34, 239-248. doi: 10.1080/08824096.2017.1286472

Rippetoe, P. A., and Rogers, R. W. (1987). Effects of components of protectionmotivation theory on adaptive and maladaptive coping with a health threat. J. Pers. Soc. Psychol. 52, 596-604.

Rogers, E. M. (2003). Diffusion of Innovations Theory, 5th Edn. New York, NY: Free Press. doi: 10.1111/j.1467-9523.1970.tb00071.x

Rogers, E. M. (2004). A prospective and retrospective look at the diffusion model. J. Health Commun. 9(Suppl. 1), 13-19. doi: 10.1080/10810730490271449

Rogers, R. W. (1983). "Cognitive and physiological processes in attitude change: a revised theory of protection motivation," in Social Psychophysiology, eds J. Cacioppo, and R. Petty (New York, NY: Guilford Press), $153-176$.

Rogers, R. W., and Mewborn, C. R. (1976). Fear appeals and attitude change: effects of a threat's noxiousness, probability of occurrence, and the efficacy of coping responses. J. Pers. Soc. Psychol. 34, 54-61.

Stuart-Smith, R. D., Brown, C. J., Ceccarelli, D. M., and Edgar, G. J. (2018). Ecosystem restructuring along the Great Barrier Reef following mass coral bleaching. Nature 560, 92-96. doi: 10.1038/s41586-0180359-9

Tabachnick, B. G., and Fidell, L. S. (2007). Using Multivariate Statistics, 5th Edn. Boston, MA: Pearson Education.

Tang, J. S., Feng, J. Y., Kothe, E. J., Ling, M., North, M., Klas, A., et al. (2018). Residents' disaster preparedness after the meinong taiwan earthquake: a test of protection motivation theory. Int. J. Environ. Res. Public Health 15:1434. doi: 10.3390/ijerph15071434

Tannenbaum, M. B., Hepler, J., Zimmerman, R. S., Saul, L., Jacobs, S., Wilson, K., et al. (2015). Appealing to fear: a meta-analysis of fear appeal effectiveness and theories HHS public access. Psychol. Bull. 141, 1178-1204. doi: 10.1037/ a0039729

Taylor, B., Vella, K., Maclean, K., Newlands, M., Ritchie, B., Lockie, S., et al. (2019). Reef Restoration and Adaption Program - Technical Process and Detailed Findings: Stakeholder, Traditional Owner \& Community Engagement Assessment. Brisbane, QLD: Australian Institute of Marine Science.

Valente, T. W., and Rogers, E. M. (1995). The origins and development of the diffusion of innovations paradigm as an example of scientific growth. Sci. Commun. 16, 242-273.

Westoby, R., and McNamara, K. E. (2019). Fear, grief, hope and action. Nat. Clim. Change 9, 500-501. doi: 10.1038/s41558-019-0511-z

Witte, K. (1992). Putting the fear back into fear appeals: the extended parallel process model. Commu. Monogr. 59, 329-349. doi: 10.1080/ 03637759209376276

Zhao, G., Cavusgil, E., and Zhao, Y. (2016). A protection motivation explanation of base-of-pyramid consumers' environmental sustainability. J. Environ. Psychol. 45, 116-126. doi: 10.1016/J.JENVP.2015.12.003

Conflict of Interest: The authors declare that the research was conducted in the absence of any commercial or financial relationships that could be construed as a potential conflict of interest.

Publisher's Note: All claims expressed in this article are solely those of the authors and do not necessarily represent those of their affiliated organizations, or those of the publisher, the editors and the reviewers. Any product that may be evaluated in this article, or claim that may be made by its manufacturer, is not guaranteed or endorsed by the publisher.

Copyright (c) 2021 Mankad, Hobman and Carter. This is an open-access article distributed under the terms of the Creative Commons Attribution License (CC BY). The use, distribution or reproduction in other forums is permitted, provided the original author(s) and the copyright owner(s) are credited and that the original publication in this journal is cited, in accordance with accepted academic practice. No use, distribution or reproduction is permitted which does not comply with these terms. 